\title{
Comparative Analysis of the Properties of Mortar Produced with Palm Kernel Oil Cake (PKOC)
}

\author{
George Okyere Dokyi ${ }^{*} \quad$ Christian Ahuma-Smith ${ }^{1} \quad$ Samson Bavuno ${ }^{2}$ \\ 1.Wa Polytechnic, Department of Civil Engineering, P. O. Box 553, Wa - UW/ R, Ghana \\ 2.Wa Polytechnic, Department of Building Technology and Estate Management, P. O. Box 553, Wa - UW/R, \\ Ghana
}

\begin{abstract}
The study explores and compares the properties of mortar produced with palm kernel oil cake (PKOC) as partial replacement of sand to traditional cement/sand mortar. Having reviewed some relevant literature on the topic, samples of materials required were collected and batched by volume to a mix proportion of (1:3). The PKOC replacement varies from $0 \%, 12.5 \%, 25 \%$ and $37.5 \%$ with water to 0.3 . A total of 16 cubes was molded, cured for 21 days, subjected to various tests at each percentage replacement. The weight and density of the PKOC samples are found to be lighter than the control sample. It was observed that the compressive strength decreases from $12.5 \%$ upwards of PKOC aggregate replacement. Also, the water absorption decreases as the PKOC aggregate replacement increases. And it was finally recommended that before one can use PKOC as a partial replacement in traditional cement/sand mortar, its content should not exceed $12.5 \%$.
\end{abstract}

Keywords: Palm kernel, palm kernel oil cake, mortar, properties of mortar

DOI: $10.7176 / \mathrm{CER} / 12-6-06$

Publication date:June $30^{\text {th }} 2020$

\section{Introduction}

Sand plays a significant role in all types of constructions, from being one of the essential elements with cement in the composition of mortar, concrete, etc. Sand winning has become so rampant that almost every land piece is vulnerable e.g., after winning the sand, pits are created and left open; when it rains, the holes hold some of the water, leading to breeding of mosquitoes. B. Agyekwena(2010) states that rivers serving as drinking water for the metropolis of Ghana are under serious threat. Their depth has reduced drastically due to siltation, which has undermined its water holding capacity. The siltation of the rivers as a result of sand winning activities along its banks poses a great danger to the metropolis. Mahmud and Jumaat (2010) stated in their study that, in many developing and underdeveloped countries in Asia and Africa, the research on the use of industrial waste products as a construction material is envisaged.

The growing concern of resource depletion and global pollution has challenged many engineers to seek and develop new materials relying on renewable resources. This includes the use of by-products and waste materials in building construction. The major problem facing the leading producers and exports of palm oil countries in the processing of palm oil is a large amount of waste produced and its environmental effects. Also, Ramli (2003) indicated that the requirement for vegetable oil is continually increasing; hence more cultivation of oil palm is forecast in the future. As the production of palm oil increases, so do the waste by-products such as palm oil kernel shell (PKS), palm kernel oil cake (PKOC), etc. However, stockpiling these wastes has been creating storage problems for the factories as large quantities of them are produced every day. Similarly, these wastes are mostly stored in open fields and harm the environment.

This research was being carried out to focus on the use of the palm kernel oil cake as partial replacement of fine aggregate to contribute to the previous study in other to minimize the problems stated above.

This study aimed to compare the properties of mortar produced with PKOC to that of traditional cement/sand mortar. To achieve the aim of the study, the following objectives were devised:

To determine the properties of mortar produce with palm kernel oil cake as a partial replacement for fine aggregate concerning density, permeability, and strength.

To determine the extent to which the identified properties vary from the traditional cement/sand mortar.

The study will be useful to academia as reference material for other researchers. The study will again make good use of palm kernel oil cake being industrial/agro-waste as a potential construction material in the construction industry. The problem concerning the disposal of (PKOC) as a waste product faced by the palm oil industries in the country will also be reduced in generating additional income to the palm oil producers when the (PKOC) is accepted.

Based on the previous study's information from the internet, books etc., this study was focused on partial replacement of (PKOC) for fine aggregate in the mortar production and the physical properties. The (PKOC) was taken from the local oil producing industries in cape coast and was used to replace river sand obtained from Kakum River at the ratio $1: 0: 3,1: 1: 2$ and $1: 1 \frac{1}{2}: 1 \frac{1}{2}$ i:e Cement : PKOC : Sand respectively. 


\section{Sustainability of PKOC as a building material in Ghana}

BOPP (2003) stated that palm fruit is known to be one of the world's productive oil crops. Five (5) tonnes of palm oil are produced by a hectare of palm fruit, which is 5 to 10 times more than the yield of any commercially grown oil crop. According to the Presidential Special Initiative (PSI, 2004), over the past twenty years, Ghana's economic performance has been inconsistent with slow rates, which generally averaged $4.6 \%$. It has been; as a result, Ghana's over-reliance on two (2) essential export commodities (cocoa and gold) and has been discovered that the main challenge facing Ghana, therefore, is how to find new pillars of growth. PSI official found that it was against this backdrop that the President in 2002 created the Presidential Initiative on Oil Palm-an action following the South African Presidential Initiatives to develop the oil palm sector. Data collected from PSI revealed that oil palm had been selected to be the new driver of Ghana's local economic development because of its potential to create many businesses in agriculture, industry, and services. A research conducted by the PSI on Oil palm in Ghana in 2004 states that there exists a large market for palm oil, and value-added palm oil-based products in Africa. There is a market for a minimum of 240,000 tonnes of crude palm for direct consumption and processing in Ghana alone. Recently, it produces less than 100,000tones leaving a shortfall of approximately 140,000 tonnes of palm oil.

The market in West Africa is approximately 2.6 million tons of palm oil. The West Africa Region currently produces about 800,000 tonnes, and it clearly shows a shortfall of 1.8 million tonnes. The breadth of oil-palm based products provides a significant opportunity for the oil palm industry in Ghana.

Akutu(1983) indicates that the quality and cost-effectiveness of construction materials employed in housing development are among the significant factors determining the optimal delivery of housing projects. Thus, materials to be used for building construction must provide objective evidence of quality and cost-effectiveness in terms of functional requirements and low-income economy, respectively. Therefore, the search for low-cost material that is socially acceptable and economically available, at an adequate quantity within reach of an ordinary man becomes a subject of continuing interest. The belief that the African region is full of raw materials suitable for local uses encourages this, yet the construction sector is not making good use of them (Ramachandran, 1983).

\subsection{PKOC as an alternative for fine aggregate (sand)}

The shortage of sand shortly due to over winning of sand from rivers, seashore, etc. is likely to be faced by construction industries in Ghana. Over-reliance on the sand for construction and other purposes as communities grow to construction at present requires less wood and more concrete, which sprout the need for low-cost sand or other alternatives. The possible ecological impact of these indiscriminate sand mining and threats to local communities' livelihoods includes the depletion of groundwater, loss of employment to farmworkers, and damage to farm roads and bridges. Extracting large quantities of quarries or pits can cause loss of valuable or scenic land, dust and noise emissions, and extra-traffic on unsuitable rural roads. (Aromolaran, 2012). As stated by Ramli (2003) That the requirement for vegetable oil is increasing, hence more cultivation of oil palm is forecast in the future. Therefore more PKOC will be produced that will be economical in the production of mortar in the construction industry.

\subsection{Extraction of Palm Kernel Oil Cake}

The African oil palm, Elaeis guineensis (Jacq.) is believed to have originated from the tropical rain forest region of West and Central Africa (Hartley 1988). It produces fruit, which is characterized by a thick fibrous, oil-rich mesocarp and a white opaque kernel embedded in a brown casing called the endocarp. The African oil palm offers the major prospect for development in that part of the plant can be put into profitable use. It produces two main commercial products: palm oil, which is approximately $22 \%$ of the weight of the fresh fruit bunch, and palm kernel cake oil represents $4-6 \%$ of the new fruit bunch. When the nut is processed, it yields palm kernel oil and palm kernel cake or meal depending on the method of extraction. According to Okeudo et al. (2005), the by-product from the mechanical expeller procedure is referred to as palm kernel cake, while that from the solvent extraction technique is called palm kernel meal. But for ease of referencing in this review, palm kernel cake and palm kernel meal are used interchangeably. Palm kernel processing in Ghana is by either one of two processes: expeller press, which yields the "Factory-type" palm kernel cake, and an indigenous local technique that produces the "Cottagetype" palm kernel cake.

Local/traditional palm oil extraction in Ghana is primarily carried out by women in the countryside. Their activities start with the purchase of nuts mainly during rainy seasons when there is an abundant supply of palm kernels, and prices are low. These women move from house to house in the oil palm processing towns buying and bulking the nuts for the palm oil production.

The nut processing and oil extraction are usually undertaken during the dry season and through the following processes:

2.2.1 Drying of kernels

The palm kernel oil extraction process begins with moisture reduction in the kernels. This is achieved in the tradition set up by storing the kernels in sacks for two to four weeks. In some cases, the kernels are spread on the 
bare ground in the open to enhance the drying process plus reduce drying time. Moisture reduction in the kernel has been identified as a pre-condition for great cracking. Good cracking results in kernels that are whole and wholly detached from the shells.

\subsubsection{Cracking}

This is mainly done by the women and their households with the help of solicited labour from other children in the vicinity. It is done by crushing the shell in between two stones. This tends to be very slow and challenging and does not prove very helpful where large quantities of nuts are processed. One advantage associated with hand cracking is that there is no need for shell and kernel separation as the kernels are separated from their nut as they are cracked.

It is common nowadays to find mechanized cracking units/mills at the various processing centers. This has become important because the throughput of these processing outfits has increased far above what can be manually cracked. The only limitation of the mechanized cracking is that the product comes out as a kernel-shell mixture, which must be separated in a different process.

\subsubsection{Kernel and shell separation}

There are two processes involved in this step. First, there is the separation by winnowing. The kernel-shell mixture is put in a container and tipped down, and as they fall, the lighter weight shell and some fibre that might have accompanied the nuts are blown away by the air current. The second step is by the use of a clay bath which operates on the principle of floatation. The clay bath is prepared to a viscosity that allows the kernels to float while the shells sink to the bottom, and the floating kernels are scooped into baskets, washed with clean water and dried. A clay bath of specific gravity 1.17 is reported to be the ideal for useful kernel and shell separation (Hartley 1988; Asiedu 1989).

\subsubsection{Oil extraction}

After drying, the kernels are roasted to release some amount of the oil and then ground into a paste in a motoroperated mill or grinder. The dough is mixed with water and boiled to release the oil from time to time, skimmed from the surface. In some localities, the kernel paste is mixed with boiling water and allowed to stay overnight, after which the oil settles on top and is then skimmed off. The solid residue is the wet palm kernel cake usually heaped in the processing centers until there is a demand for it. If there is none, it is virtually abandoned to become a substrate for mould growth and also pollute the environment.

\subsection{PKOC as a building material}

Given the abundance of PKOC in many West African countries, the potential as a cheap material for feeding livestock must be fully exploited. The inability to do so thus far can be attributed to either the lack of the flow of information on chemical compositions, nutritive values, improvement methods, and feeding responses of animals feed palm kernel cake-based diets.

\subsection{Mortar}

This is a combination of cement and fine aggregate that is used to hold together construction type blocks. When water is added, it becomes a workable paste that sets hard. It is used with materials like bricks and stones to make walkways and walls (GEEK, 2013). Bob (2011) defines mortar as a mixture of sand and cement that is most often used to build bricks or block walls.

The leanest workable Portland cement mix is 1 volume Portland cement to 3 volumes of clean sand, but such a mix is more potent than required for most purposes. By substituting non-hydraulic or semi-hydraulic lime to BS 890 for part of the cement in a 1:3 mix, strength and the tendency to crack can be reduced while improving workability, water retention, and bonding properties. 1 Portland cement: 2 lime: 9 sand mixes are about 10 percent weaker than, and 1:3:12 mixes about 20 percent weaker than 1 Portland cement: 3 sand. BS 4721 describes Readymixed lime-sand for mortar-mainly for gauging with cement. BS 5838 requires bricklaying and masonry mortar, to have a minimum crushing strength of $3 \mathrm{~N} / \mathrm{mm} 2$ at 28 days.

\section{Materials and Methods}

The Portland limestone cement 32.5R produced by Ghana Cement Limited (GHACEM) has been Ghana's largest cement producer and, as such, accessible in almost every part of Ghana, was used for all the mixes required for this study. This cement also conforms to the requirements of the British Standard Code (BS 12 of 1996) and requirements of GS 22 (2004). It was kept in tight air packages and stored inside the laboratory to prevent the cement from being exposed to moisture and hardened before usage. Water produced by Ghana Water Company Limited was used in mixing materials. It conformed to BS 1348 (1980) and looked clean and also free from any visible impurities. The fine aggregates (sand) used was clean, sharp river sand obtained from Kakum River that is free from clay, loam, dirt and organic matter of any description and it was sieved to fulfil the requirement of $100 \%$ passing through the $75 \mathrm{~mm}$ sieve and $100 \%$ retained on the $4.75 \mathrm{~mm}$ sieve BS 812: Part 103.1 (1985). The PKOC that was used for the study is the industrial waste stockpiled by the local palm kernel oil producing industries in 
Ghana. Due to the nearness of the researcher to palm kernel oil production site in Cape Coast (Ensuekyire), the PKOC was sourced from there. However, after the oil is being extracted, the waste contains some oil content, and because oil is not the right agent in bonding building materials together, the waste that has been stockpiled for long and the oil been washed away was used.

\subsection{Mixing process}

Hand mixing was adopted to produce the samples. According to cement and concrete institute, it is possible to make blocks on a small scale without a concrete mixer. Measures were put in place to control deficiencies. Before mixing, all the components were weighed according to the mix proportions. A block size of $100 \times 100 \times 100 \mathrm{~mm}$ was produced under laboratory conditions for the study.

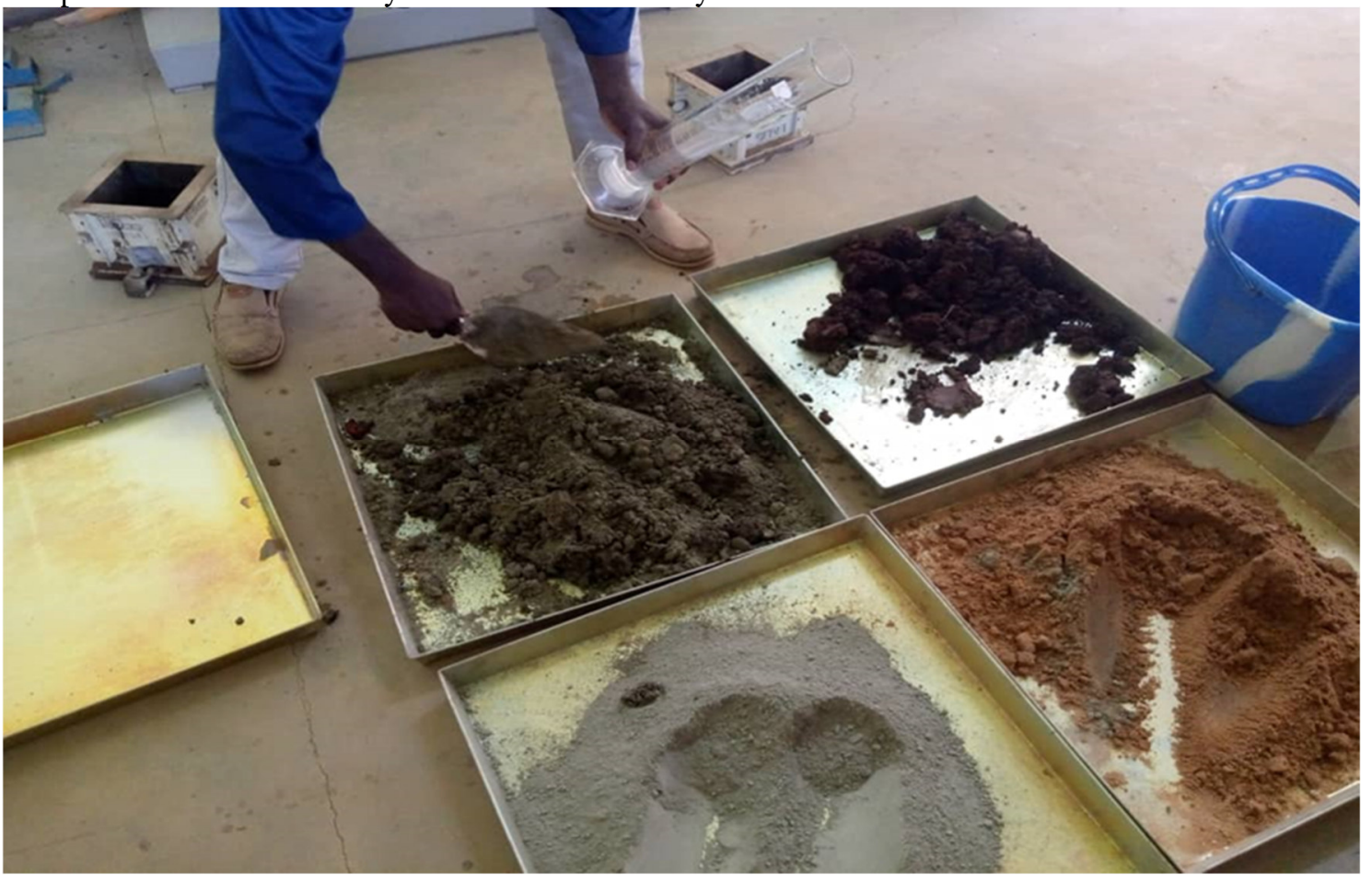

Fig 1: Mixing of materials for samples

The mix ratio used is 1:3 (one part of cement to three parts of sand). The sand was replaced partially with the PKOC in the ratio indicated in table 3.1. Table 3.1: Ratio of materials for the study

\begin{tabular}{|l|l|l|l|l|}
\hline Mix & Cement & PKOC & Sand & PKOC \% \\
\hline Control Mix(1:0:3) & 1 & 0 & 3 & 0 \\
\hline $1: 1 \frac{1}{2: 21 / 2}$ & 1 & $1 / 2$ & 2 & 12.5 \\
\hline $1: 1: 2$ & 1 & 1 & 2 & 25 \\
\hline $1: 1 \frac{1}{2}: 1 \frac{1}{2}$ & 1 & 1 & 1 & 37.5 \\
\hline
\end{tabular}

Samples were mould in cubes of $100 \times 100 \times 100 \mathrm{~mm}$ and four (4) per mix design, in all a total of sixteen (16) samples for the study. The samples after a day of production were stacked in the area ready for curing in other to gain strength and to ensure sufficient hydration of the cement.

In coming out with the properties of mortar produced with palm kernel oil cake as a partial replacement for fine aggregate, an experimental investigation was conducted to the study the following properties: weight/density, water absorption, and compressive strength. 


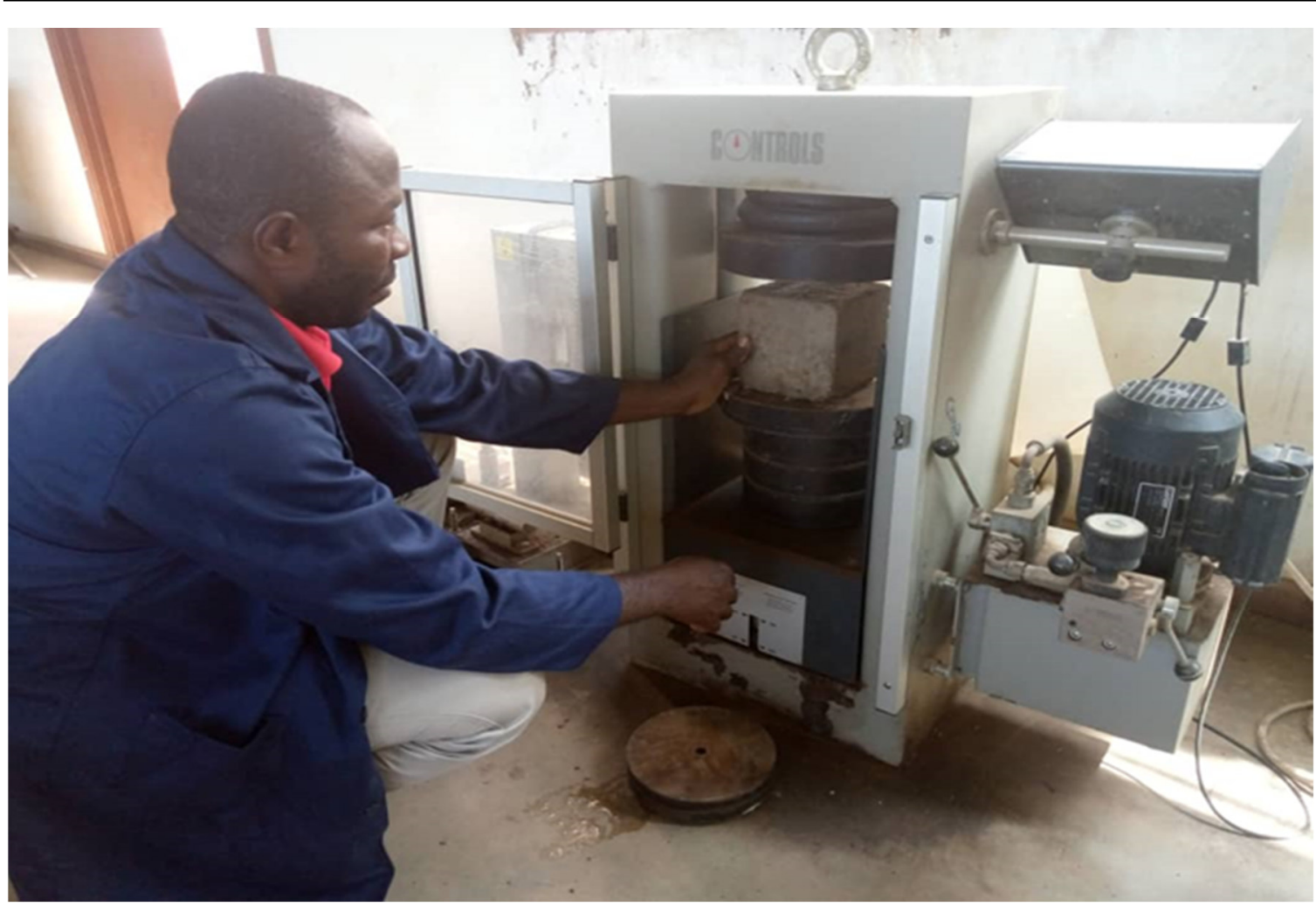

Fig 2: Crashing of Blocks samples

The arrangement of the experimental program can be summarized in the flow chart shown in figure 3 .

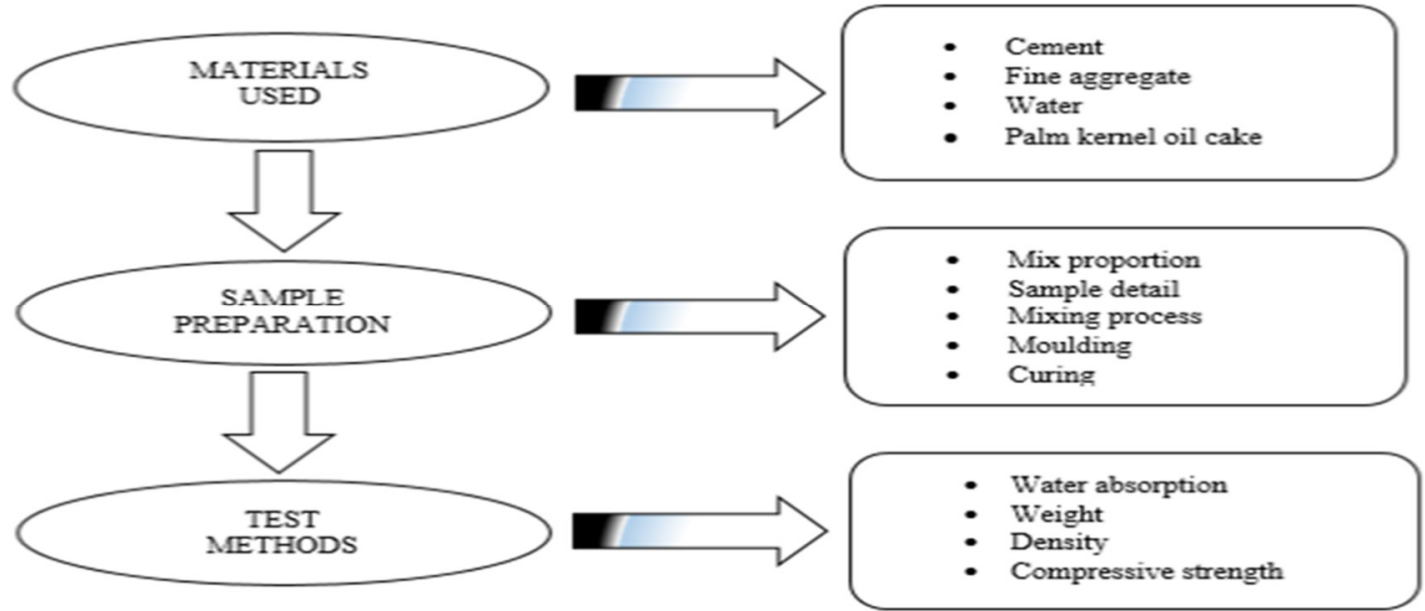

Fig. 3: Flow chart of experimental programme

\section{Results and Discussion}

4.1 Water Absorption

Result of Water Absorption Test is presented in figure 4.1 and figure 4.2 as shown below. 


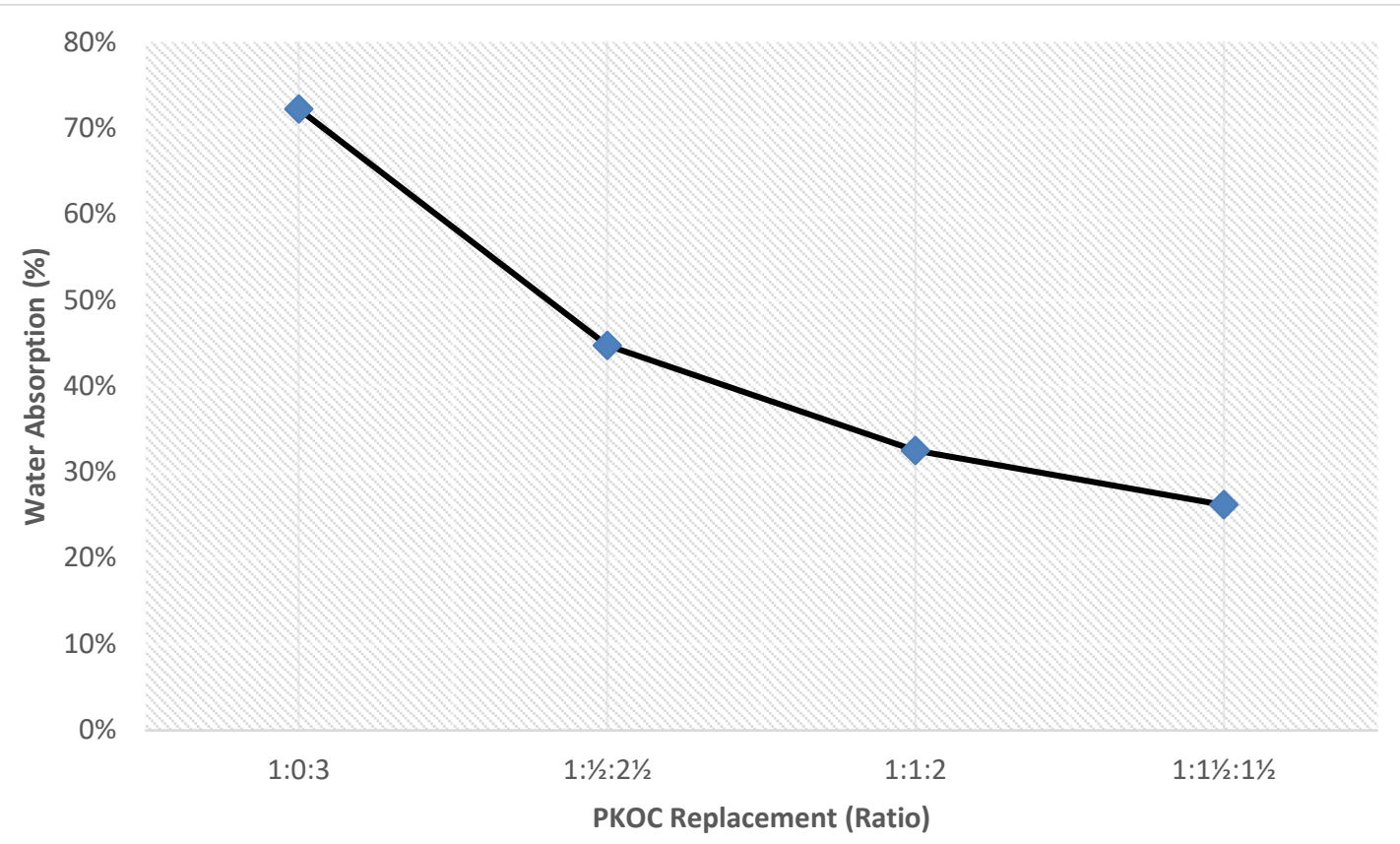

Figure 4.1: Relationship between percentage PKOC replacement and water absorption

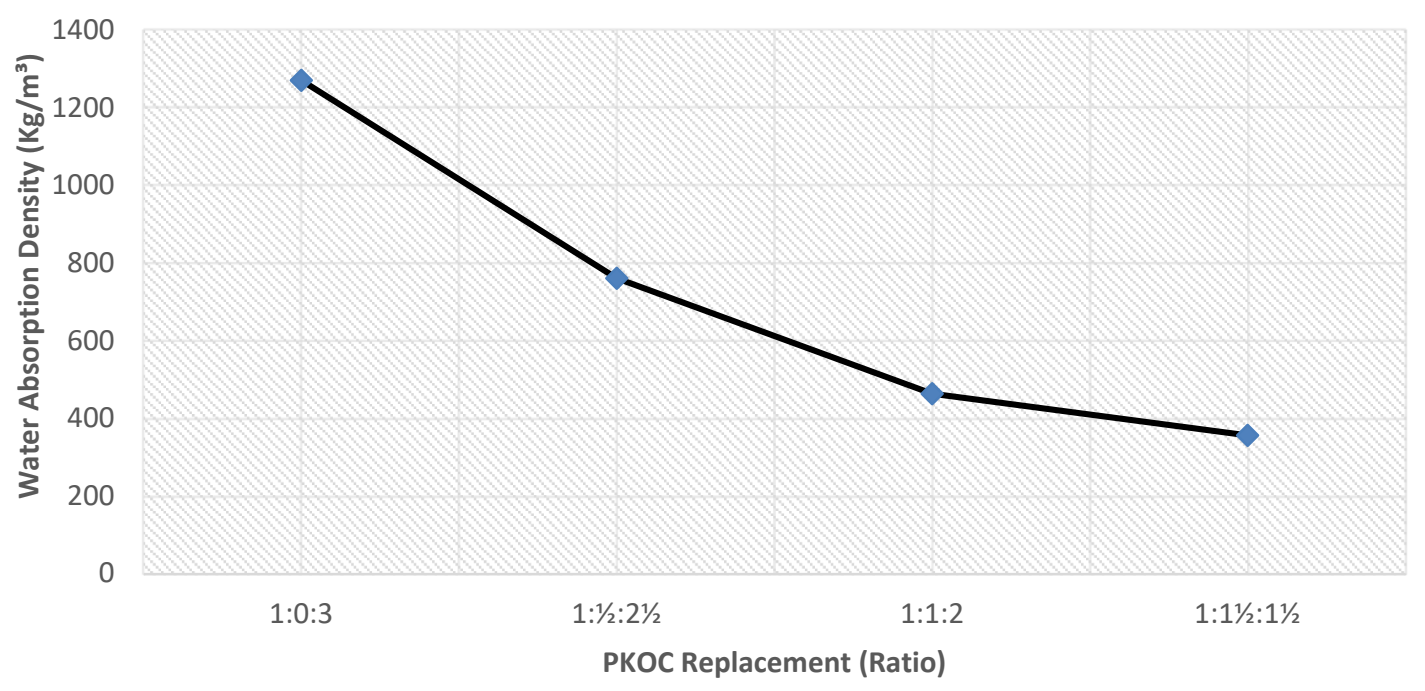

Figure 4.2: Relationship between percentage PKOC replacement and water absorption Density

Table 4.1: Water Absorption of Cube

\begin{tabular}{|c|c|c|c|c|}
\hline $\begin{array}{c}\text { PKOC } \\
\text { Replacement } \\
\text { (Ratio) }\end{array}$ & $\begin{array}{c}\text { Dry Mass } \\
(\mathbf{k g})\end{array}$ & $\begin{array}{c}\text { Wet Mass } \\
(\mathbf{k g})\end{array}$ & $\begin{array}{c}\text { Water } \\
\text { Absorption } \\
(\%)\end{array}$ & $\begin{array}{c}\text { Water Absorption } \\
\text { Density } \\
\left(\mathbf{K g} / \mathbf{m}^{\mathbf{3}}\right)\end{array}$ \\
\hline $1: 0: 3$ & $\mathbf{1 . 7 6 1}$ & $\mathbf{3 . 0 3 2}$ & $\mathbf{7 2 \%}$ & $\mathbf{1 2 7 1}$ \\
\hline $1: 1 / 2: 21 / 2$ & $\mathbf{1 . 7 0 1}$ & $\mathbf{2 . 4 6 2}$ & $\mathbf{4 5 \%}$ & $\mathbf{7 6 1}$ \\
\hline $1: 1: 2$ & $\mathbf{1 . 4 2 8}$ & $\mathbf{1 . 8 9 2}$ & $\mathbf{3 2 \%}$ & $\mathbf{4 6 4}$ \\
\hline $1: 1 \frac{1}{1}: 11 \frac{1}{2} 2$ & $\mathbf{1 . 3 6 2}$ & $\mathbf{1 . 7 1 9}$ & $\mathbf{2 6 \%}$ & $\mathbf{3 5 7}$ \\
\hline
\end{tabular}

The table4.1 above shows the relationship between water absorption between samples. It could be clearly seen from the table that the amount of water absorbed by the samples reduces as the percentage replacement of the PKOC increases. Aside that, the water absorption of the control sample is $1.761 \mathrm{~kg} / \mathrm{m} 3$, the values from $12.5 \%$ to $37.5 \%$ ranges from $0.761 \mathrm{~kg} / \mathrm{m} 3$ to $0.357 \mathrm{~kg} / \mathrm{m} 3$. The resulting decrease in water absorption of the samples as the PKOC content increases can be a result of the smoothness of the PKOC. 


\subsection{Weight/Density}

The properties concerning weights and densities of samples produced are shown in figures 4.2 and 4.3 . It can be seen clearly that the relationship is the same. It is also found that the more the PKOC, the lighter the weight of the cube. This is because the PKOC is light in weight. Referring to the values on the sample of $12.5 \%$, PKOC aggregate replacement is found to be lighter than $(1.734 \mathrm{~kg}$ and $1.734 \mathrm{~kg})$ as compared to the control sample of $0 \%$ PKOC aggregate replacement $(1.848 \mathrm{~kg}$ and $1.848 \mathrm{~kg})$. It could be noticed that from $25 \%$ upward PKOC replacement, the values for both the weights and densities decrease. This indicates that for a better partial replacement of PKOC percentage for sand in mortar production, $12.5 \%$ is useful if the emphasis is solely on the weight or density.

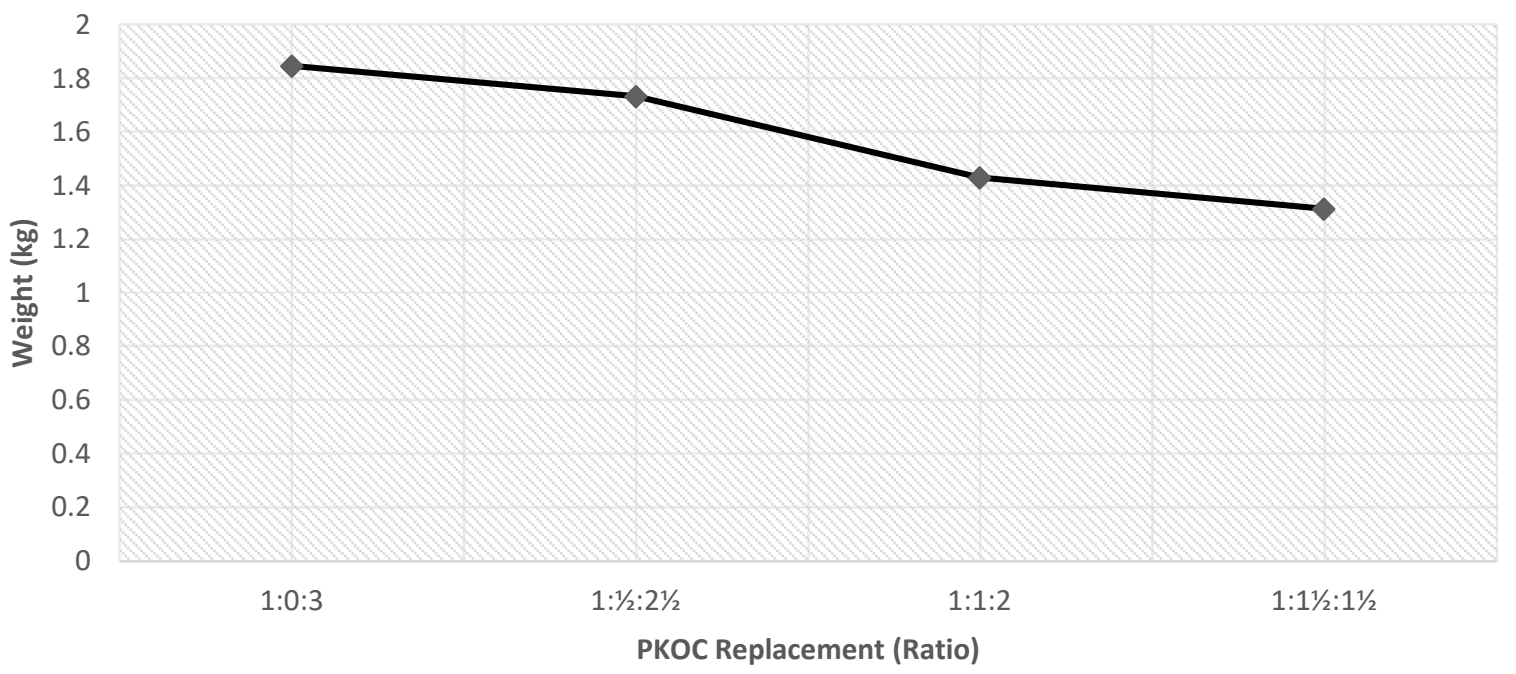

Figure 4.3: Relationship between percentage PKOC replacement and sample weight

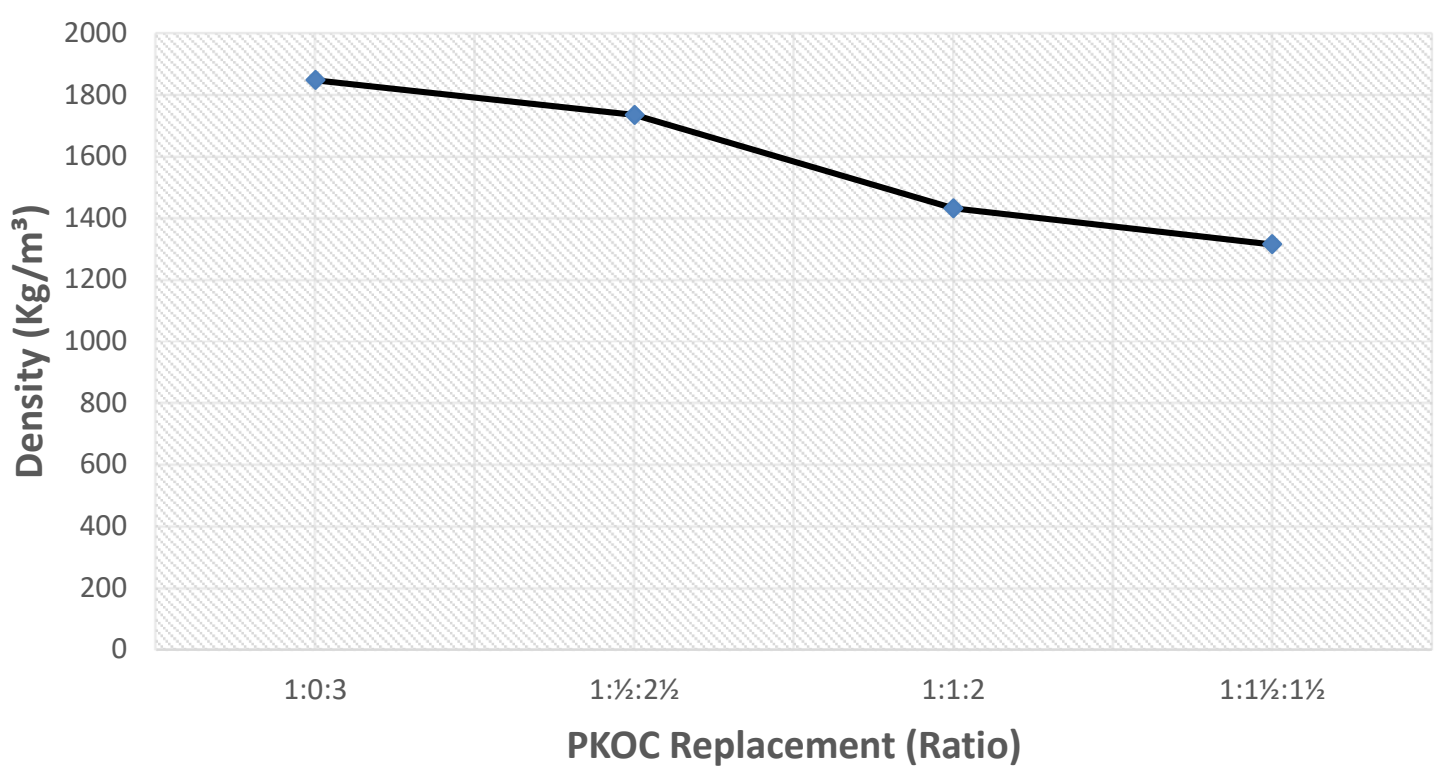

Figure 4.4: Relationship between percentage PKOC replacement and sample density

Table 4.2: Weight of Cube Samples

\begin{tabular}{|c|c|c|c|c|}
\hline \multirow{2}{*}{$\begin{array}{c}\text { PKOC } \\
\text { Replacement } \\
\text { (Ratio) }\end{array}$} & \multicolumn{3}{|c|}{ Weight(kg) } & \multirow{2}{*}{$\begin{array}{c}\text { Average Weight } \\
\text { (kg) }\end{array}$} \\
\hline & Sample 1 & Sample 2 & Sample 3 & \\
\hline $1: 0: 3$ & 1.761 & 1.933 & 1.849 & 1.848 \\
\hline $1: 1 / 2: 21 / 2$ & 1.701 & 1.767 & 1.733 & 1.734 \\
\hline $1: 1: 2$ & 1.428 & 1.444 & 1.421 & 1.431 \\
\hline $1: 11 / 2: 11 / 2$ & 1.362 & 1.322 & 1.260 & 1.315 \\
\hline
\end{tabular}


Table 4.3: Densities of cube samples

\begin{tabular}{|c|l|c|c|c|}
\hline \multirow{2}{*}{$\begin{array}{c}\text { PKOC } \\
\text { Replacement } \\
(\text { Ratio) }\end{array}$} & \multicolumn{3}{|c|}{ Density $\left(\mathrm{Kg} / \mathrm{m}^{3}\right)$} & \multirow{2}{*}{$\begin{array}{c}\text { Average Density } \\
\left(\mathrm{Kg} / \mathbf{m}^{3}\right)\end{array}$} \\
\cline { 2 - 5 } & Sample 1 & Sample 2 & Sample 3 & 1.848 \\
\hline $1: 0: 3$ & 1.761 & 1.933 & 1.849 & 1.734 \\
\hline $1: 1 / 2: 21 / 2$ & 1.701 & 1.733 & 1.767 & 1.431 \\
\hline $1: 1: 2$ & 1.428 & 1.421 & 1.444 & 1.315 \\
\hline $1: 1 \frac{1}{1}: 11 / 2$ & 1.362 & 1.322 & 1.260 & \\
\hline
\end{tabular}

\subsection{Compressive Strength}

The figure 4.5 below shows the relationship between the control mix and PKOC in terms of compressive strength. It can be clearly seen that the value of the control mix is higher than that of the PKOC aggregate replacement. The value for the control sample $(3.47 \mathrm{~N} / \mathrm{mm} 2)$ and PKOC aggregate replacement from $(1.134 \mathrm{~N} / \mathrm{mm} 3,1.105 \mathrm{~N} / \mathrm{mm} 2$, and $1.060 \mathrm{~N} / \mathrm{mm} 2$ ) clearly shows the strength between them. It is also observed from the figure that the compressive strength decreases from $12.5 \%$ upwards of PKOC aggregates replacement.

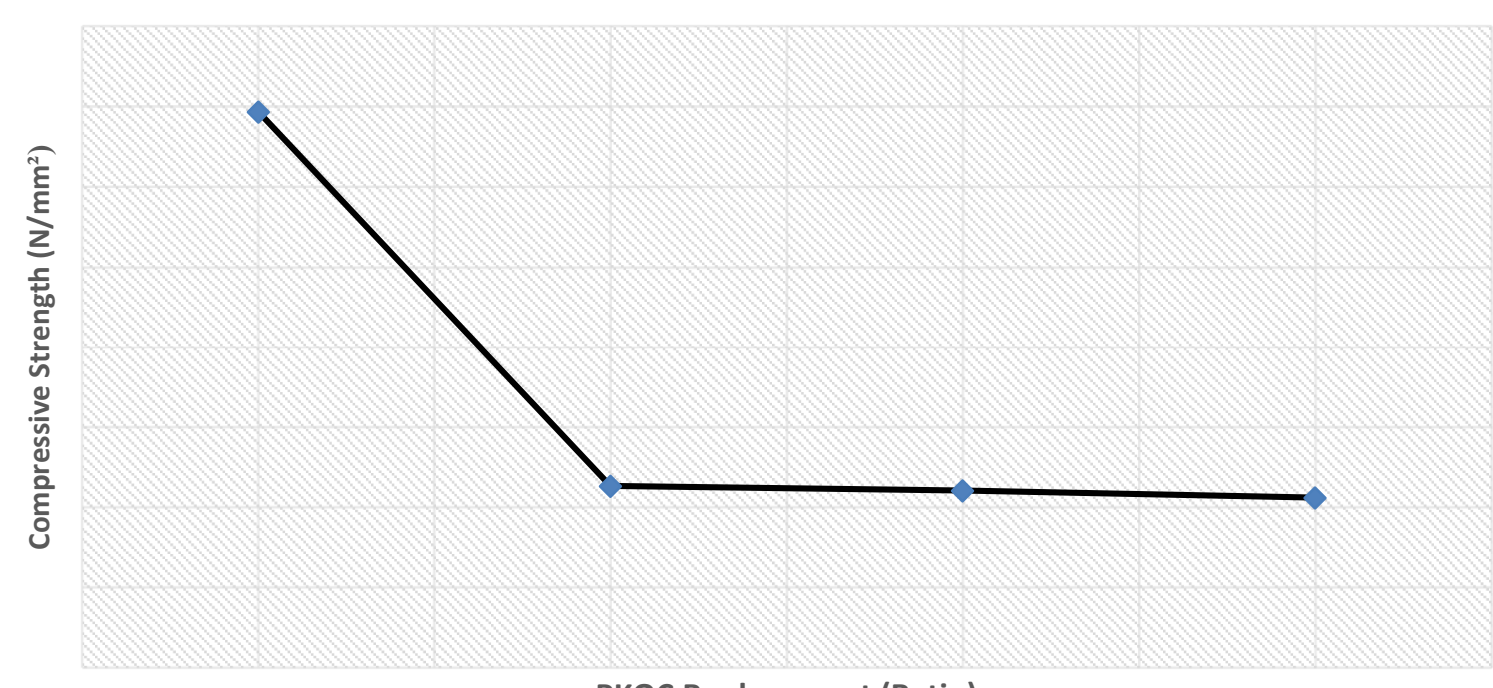

PKOC Replacement (Ratio)

Figure 4.5: Relationship between percentage PKOC replacement and compressive strength of sample

Table 4.4: Compressive Strength of Cube Samples

\begin{tabular}{|c|c|c|c|}
\hline \multirow{2}{*}{$\begin{array}{c}\text { PKOC } \\
\text { Replacement } \\
\text { (Ratio) } \\
\end{array}$} & \multicolumn{2}{|c|}{ Compressive Strength(N/mm²) } & \multirow{2}{*}{$\begin{array}{c}\text { Average } \\
\text { Compressive } \\
\text { Strength }\left(\mathrm{N} / \mathrm{mm}^{2}\right)\end{array}$} \\
\hline & Sample 1 & Sample 2 & \\
\hline $1: 0: 3$ & 3.644 & 3.296 & 3.47 \\
\hline $1: 1 / 2: 2 \frac{1}{2}$ & 1.159 & 1.160 & 1.134 \\
\hline $1: 1: 2$ & 1.101 & 1.109 & 1.105 \\
\hline $1: 11 / 2: 11 / 2$ & 1.092 & 1.029 & 1.060 \\
\hline
\end{tabular}

Table 4.5: Compressive Load of Cube Samples

\begin{tabular}{|c|l|c|c|}
\hline \multirow{2}{*}{$\begin{array}{c}\text { PKOC } \\
\text { Replacement } \\
(\%)\end{array}$} & \multicolumn{2}{|c|}{ Compressive Load (KN) } & \multirow{2}{*}{$\begin{array}{c}\text { Average } \\
\text { Compressive Load } \\
\text { (KN) }\end{array}$} \\
\cline { 2 - 3 } & Sample 1 & Sample 2 & 34.702 \\
\hline 0 & 36.439 & 32.964 & 11.308 \\
\hline 12.5 & 11.593 & 11.604 & 11.052 \\
\hline 25 & 11.012 & 11.092 & 10.608 \\
\hline 37.5 & 10.921 & 10.295 & \\
\hline
\end{tabular}

\section{Conclusion}

The study reveals that the properties in terms of weight/density are the same, and more then PKOC, the cubes become lighter in weight due to the smoothness of the PKOC. It is also observed that the compressive strength 
decreases as the PKOC replacement increases. Finally, it was observed that the amount of water absorbed by the control mix is more than that of the PKOC, and it also reduces as the percentage replacement increases the PKOC's smoothness of the PKOC.

Based on the results of the various test carried out, it was concluded that; in terms of weight/density the properties are the same, and the PKOC samples are lighter in weight than that of traditional cement and river sand. Secondly, the compressive strength of the conventional cement and sand samples is more than that of PKOC, and the water absorption is less in the PKOC and high in the traditional cement and river sand.

The following recommendations were made based on the results obtained;

i. in terms of compressive strength, the PKOC should not be more than the river sand in the production of mortar for plastering at most $12.5 \%$.

ii. Also, due to lighter in weight, it is recommended that this type of mortar should be used on non-load bearing walls.

Finally, due to less water absorption, the mortar produced with PKOC can withstand moisture penetration more than traditional cement sand mortar.

\section{References}

Akutu, G. O. (1983), 'Reducing the Cost of Building Project', IMT Building Journal, Enugu: Chika Printing Company.

Aromolaran, A. K. (2012), 'Effects of sand mining activities on land in Agraian communities of Ogun state, Nigeria', Continental J. Agricultural Science, 6 (1), 41-49.

Asante, C. K. O. \& Baiden, B. K. (2004), 'Effect of orientation and compaction method of manufacture on strength properties of sandcrete block'. Construction and Building Materials, Elsevier 18, 717 - 725.

Duggal, S. K. (2003), Building Materials. New Age International Publishers, New Delhil, India.

Handoo, B. L., Puri, L. D. \& Mahmud, H. (1975), Concrete Technology (7th edn.). New Delhi: Satya Prakashan, 16/7698,New Market, New Rohtak Rd. ISBN 81-7684-081-5

Hartley, C. W. S., 1988; Boaten, M., Okai, D. B., \& Donkoh, A. (2008), 'Palm kernel cake extraction and utilisation in pig and poultry diets in Ghana', Livestock Research for Rural Development Vol. 20, Article \#99

Jackson, N. \& Dhir, K. R. (1988), Civil Engineering Materials (4th edn.) McMilan Press Ltd. London, England. ISBN 0-333-48828-8, pp. 405-411

Kreh, R. T. (2003), Masonry Skills (5th edn.). USA: Thomson Learning, Inc. ISBN 0-7668-5936-3, pp. 33-94.

Mahmud, H., \& Jumaat, M. Z., ( 2010) 'Structural Behavior of reinforced palm kernel shell foamed concrete beams: Challenges, Opportunities and Solution in Structural Engineering and Construction', Ghafoori (ed.). London: Taylor and Francis Group. IISB 978-0-415-56809-8, pp. 265-270.

Okeudo, N. J., Eboh, K. V., Ndidi, V. I., \& Akanno, E. C., (2005), 'Growth rate, Carcass Characteristics and Organoleptic quality of broilers fed graded levels of palm kernel cake'. International Journal of Poultry Science 4 (5): 330-333

President Special Initiative -Oil Palm, (2004 )Project Report and the PSI - Oil Palm 2004 Progress Report (Addendum to Inception Report). Ghana

Ramachandran, A. (1983). Appropriate Building Materials for Low Cost Housing in Africa. A Symposium Proceeding on November. Nairobi

Ramli, R. B., (2012), "An investigation on the strength and workability of concrete using Palm Kernel shell and Palm Kernel Fibre as a coarse aggregate", International Journal of Scientific \& Engineering Research, Vol. 3, Issue 4, ISSN: 2229 - 5518

Taylor, G. D., (1991). Construction Materials. UK: Longman Group Ltd. ISBN 0-582-04299-2 